
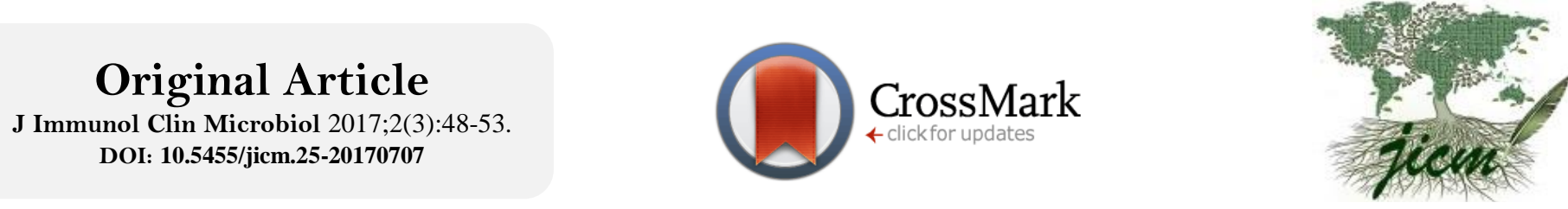

J Immunol Clin Microbiol

\title{
Differentiation between vaccinal and field strains of $E$. coli using phenotype and genotype characterization
}

\author{
Fatma El-Zahraa Gamal ${ }^{1}$, Fatma Gadallah ${ }^{1}$, Moustafa Zaghloul ${ }^{1}$, \\ Ekram Salama $^{1}$, Selim Salama ${ }^{1 *}$, Afaf Khedr ${ }^{1}$ \\ ${ }^{1}$ Central Lab for Evaluation of Veterinary Biologics, Abbasia, Cairo, Egypt.
}

\begin{abstract}
Background: E. coli infection is considered as an important bacterial problem associated with significant economic losses and usually associated with a variety of disease conditions, including acute septicaemia, haemorrhagic enteritis, pericariditis, salpingitis and complicated air saculitis. These considerations suggest that control of $E$. coli by vaccination could be of great value especially live vaccine that based on defined mutations that impair and non-revering virulence.

Material and Methods: Wild type 078 strain, Live 078 aro $A$ gene deleted vaccine and Live 078 crp gene deleted vaccine were used to accomplish this study. Phenotypic characterization was adopted by studying the cultural, biochemical and serological properties. Also genotypic characterization was studied for $16 S$ rRNA, aroA and crp genes.

Results: Growth pattern on different media differed among the used strains as the wild type and $\Delta$ aroA mutant were nearly similar while the $\Delta$ crp mutant strain was greatly differed. Biochemically the difference between the wild-type and $\Delta$ aroA mutant was inability of mutant strain to produce arginine dihydrase (ADH) and fermentation of saccharose. On the other hand the $\Delta$ crp mutant failed to produce ADH and to ferment any of the carbohydrates except glucose. A successful amplification of the $16 S$ rRNA gene at $585 \mathrm{bp}$ was detected with the all tested strains while was $1206 \mathrm{bp}$ with only wild type and $\Delta$ crp mutant strain when aroA gene primers were used. Regarding $\operatorname{crp}$ genes, the amplified products was at $1029 \mathrm{bp}$ with the wild and $\Delta$ aroA mutant but not with $\Delta$ crp mutant strains.

Conclusion: Findings of this study prove the use of methods based on molecular techniques like PCR to differentiate between different types of E. coli either wild or vaccinal mutant type strains. Also it may help in exclusion or proving the return back to virulence of the mutant vaccinal strains.
\end{abstract}

Key words: E. coli O78, chickens, phenotypic characterization, genotypic characterization, wild and vaccinal mutant strains.

\section{Introduction}

Escherichia coli $($ E. coli) is a gram-negative bacteria that belong to the family Enterobacteriaceae and considered as a member of the commensal intestinal flora in animals. It may sometimes produce pathogenic strains (1). E. coli infection is one of the most important bacterial diseases affecting chicken, resulting in significant economic losses through mortality, morbidity, cost of treatment and condemnation at processing plant (2).

*Corresponding Author: Selim Salama, Central Lab for Evaluation of Veterinary Biologics, Abbasia, Cairo, Egypt. E-mail: selimsalama2000@yahoo.com Received: Mar 08, 2017 Accepted: Jul 07, 2017.
The infection has been associated with a variety of disease conditions, including acute septicaemia, haemorrhagic enteritis, pericariditis, salpingitis and complicated air sacculitis (3). More than one hundred E. coli serotypes have been reported but the infection in chickens was mostly belonged to serogroups $\mathrm{O} 1, \mathrm{O} 2$ and $\mathrm{O} 78$ (4). This infection is treated with expensive antibiotics, often resulting in the subsequent development of resistant strains that prevent continued use of effective treatment.

This is an Open Access article distributed under the terms of the Creative Commons Attribution Non-Commercial License (http://creativecommons.org/licenses/bync/4.0/) which permits unrestricted non-commercial use, distribution, and reproduction in any medium, provided the original work is properly cited. 
These considerations suggest that control of such condition by vaccination could be of great value (5). Alive vaccine based on defined mutations that impair virulence and non-revering may meet the requirements for application in commercial operation. Deletion mutation (identified by the symbol $\Delta$ ) in aroA gene (a gene that codes 5-enolpyruvylshikimate 3-phosphate synthase, one of enzymes that govern the shikimate pathway for synthesizing aromatic amino acids involved with the growth and metabolism of bacteria) and crp gene (gene for cAMP receptor protein) have been shown to reduce the virulence of $E$. coli strains $(6,7)$.

The present study is undertaken with the aim to differentiate between the field or wild $E$. coli strains and the recently widely used live vaccinal strain of $E$. coli among poultry clusters using either phenotypic specification or genotypic characterization.

\section{Methods and materials}

\section{E. coli strains}

A wild type strain and two mutant vaccinal strains used in this study. The wild type O78 strain was isolated and identified in the Central Laboratory for Evaluation of Veterinary Biologics (CLEVB), Cairo, Egypt. The mutant strains are: Live 078 aroA gene deleted vaccine $(\triangle \operatorname{aro} A$ $E$. coli mutant vaccinal strain) and Live O78 crp gene deleted vaccine ( $\Delta$ crp E. coli mutant vaccinal strain).

\section{Phenotypic differentiation}

Phenotypic differentiation was performed by colony morphology, microscopic examination, motility, biochemical identification and serological differentiation as follows:

Colonial morphology: The wild type 078 strain and their corresponding mutants ( $\triangle$ aroA and $\Delta$ crp vaccinal strains) were cultivated onto nutrient agar, MacConkey agar, and Salmonella Shigella agar to differentiate their macroscopic colonial characters. Microscopic examination: Smears from freshly growing colonies were stained with Gram stain and examined microscopically. Motility: Motility was assured by growing and spreading of the wild type and vaccinal strains by stabbing in semisolid agar. Biochemical identification: Pure cultures of vaccinal and wild type strains were examined biochemically by using API 20E identification system according to (8) following the procedures of kit manual. Serological differentiation: Both vaccinal and wild type strains were subjected to serological differentiation according to procedures described by (9) using polyvalent diagnostic antisera (O6, $\mathrm{O} 27, \mathrm{O} 78, \mathrm{O} 148, \mathrm{O} 159, \mathrm{O} 168)$ then each monospecific diagnostic antisera.

\section{Genotypic characterization \\ DNA Extraction}

DNA templates from the vaccinal and wild type $E$. coli strains were extracted using Isolate Genomic DNA Mini Kit. (Bioline) (6).

\section{Primers pairs}

Specific primers for $16 s$ rRNA, aroA and crp genes were used as listed in Table (1).

Table 1. Primers used for amplification of $16 s R N A$, aroA and $c r p$ genes.

\begin{tabular}{llll}
\hline Genes & Primer Sequence & Product & Reference \\
\hline $16 s$ & F5-GAC CTC GGT TTA GTT & $585 \mathrm{bp}$ & 10 \\
$r R N A$ & CAC AGA-3 & & \\
& R5-CAC ACG CTG ACG CTG & & \\
& ACCA-3 & & \\
\hline aro A & F5-CAT GGT ACC TCG TGT & $1206 \mathrm{bp}$ & 6 \\
& CGA TGG CAC TAT TA-3 & & \\
& R5-GCC GAG CTC TCA AGA & \\
& ATC GTC ACT GGT GT-3 & & \\
\hline$c r p$ & F5-CTG ACG ACC AGA GGC & $1029 \mathrm{bp}$ & 7 \\
& GGA TT-3 & & \\
& R5-CTA CCA GGT AAC GCG & & \\
& CCA CT-3
\end{tabular}

\section{Polymerase chain reaction $(\mathrm{PCR})$ assay}

$5 \mu \mathrm{l}$ of genomic DNA, $12.5 \mu \mathrm{l}$ of dream taq green master mix (Thermoscientific), $1 \mu \mathrm{l}$ of each primer (10 pmole) and $5.5 \mu 1$ of deionized water were added to $0.5 \mathrm{ml}$ micro centrifuge tubes. The amplification reactions were performed under following conditions: $94^{\circ} \mathrm{C}$ for $4 \mathrm{~min}$, then 29 cycles each at $94^{\circ} \mathrm{C}$ for $90 \mathrm{sec}, 62^{\circ} \mathrm{C}$ for $90 \mathrm{sec}$ and $72^{\circ} \mathrm{C}$ for $2 \mathrm{~min}$.; lastly $72^{\circ} \mathrm{C}$ for $10 \mathrm{~min}$ for $16 \mathrm{SrRNA}(10)$, $94^{\circ} \mathrm{C}$ for $3 \mathrm{~min}$, then $30 \mathrm{cycles}$ each at $94^{\circ} \mathrm{C}$ for $45 \mathrm{sec}$, $60^{\circ} \mathrm{C}$ for $30 \mathrm{sec}$ and $72^{\circ} \mathrm{C}$ for $45 \mathrm{sec}$.; lastly $72^{\circ} \mathrm{C}$ for $7 \mathrm{~min}$ for aroA gene (6) and $94^{\circ} \mathrm{C}$ for $4 \mathrm{~min}$, then 30 cycles each at $94^{\circ} \mathrm{C}$ for $1 \mathrm{~m}, 60^{\circ} \mathrm{C}$ for $1 \mathrm{~min}$ and $72^{\circ} \mathrm{C}$ for $90 \mathrm{sec}$.; lastly $72^{\circ} \mathrm{C}$ for $6 \mathrm{~min}$ for $\mathrm{crp}$ gene (7). The PCR products were analyzed on $1 \%$ agarose gel.

\section{Results}

In the present study, the phenotypic and genotypic characterizations were used to differentiate between the wild-type 078 strain, $\Delta$ aroA and $\Delta$ crp mutant vaccinal strains.

Growth on different media: The pattern of growth on different media when incubated at $37 \mathrm{C}^{\circ}$ for $24 \mathrm{hrs}$ differed among the wild type and the two types of mutant colonies. As shown in Table 2, wild type and $\triangle$ aroA mutant demonstrated a large sized rounded, non-pigmented colonies on nutrient agar medium and large sized fermenting rounded, non-mucoid colonies on MacConkey and SS media. Concerning the $\Delta$ crp mutant strain, it 
showed small sized rounded, non-pigmented colonies on Nutrient agar medium and small sized non-fermenting rounded, non-mucoid phenotype on MacConkey and SS median. Both wild and two mutant strains were Gram negative, motile, non-sporulated, medium sized bacilli.

Table 2. Colonial and microscopic characteristics of the E. coli strains.

\begin{tabular}{|c|c|c|c|c|c|}
\hline \multirow{2}{*}{$\begin{array}{l}\text { E. coli } \\
\text { strains }\end{array}$} & \multicolumn{3}{|c|}{ Media } & \multirow[t]{2}{*}{ Motility } & \multirow[t]{2}{*}{ Gram stain } \\
\hline & $\begin{array}{c}\text { Nutrient } \\
\text { agar }\end{array}$ & $\begin{array}{c}\text { MacConkey } \\
\text { agar }\end{array}$ & $\begin{array}{c}\text { SS } \\
\text { agar }\end{array}$ & & \\
\hline $\begin{array}{c}\text { O78 } \\
\text { strain }\end{array}$ & $+v e$ & $+v e$ & $+v e$ & $+v e$ & \multirow{3}{*}{$\begin{array}{l}\text { Gram } \\
\text { negative, } \\
\text { non- } \\
\text { sporulated, } \\
\text { medium } \\
\text { sized bacilli }\end{array}$} \\
\hline $\begin{array}{l}\triangle a r o A \\
\text { mutant }\end{array}$ & $+\mathrm{ve}$ & $+\mathrm{ve}$ & $+v e$ & $+v e$ & \\
\hline $\begin{array}{c}\text { Acrp } \\
\text { mutant }\end{array}$ & $+v e$ & -ve & -ve & $+v e$ & \\
\hline
\end{tabular}

Biochemical Activity: Depending on the results of API 20E identification system as demonstrated in Table (3) and Figure (1), the wild type O78 strain showed positive results with ONPG,ADH, LDC, ODC, IND, GLU, MAN, SOR, RHA, SAC, MEL and ARA tests and negative results with CIT, H2S, URE, TDA, VP, GEL, INO, AMY and $\mathrm{OX}$ tests meanwhile the $\triangle$ aroA mutant gave positive reaction with ONPG, LDC, ODC, IND, GLU, MAN,SOR, RHA, MEL and ARA tests and negative reaction with ADH, CIT, H2S, URE, TDA, VP, GEL, INO, SAC, AMY and $\mathrm{OX}$ tests. On the other hand, the $\Delta$ crp mutant give positive results with ONPG, LDC, ODC, IND, GLU and ARA tests and negative results with ADH, CIT, H2S, URE, TDA, VP, GEL, MAN, INO, SOR, RHA, SAC, MEL, AMY and OX tests.

Table 3. API 20E characteristics of different types of E. coli strains.

\section{API 20E RESULTS}

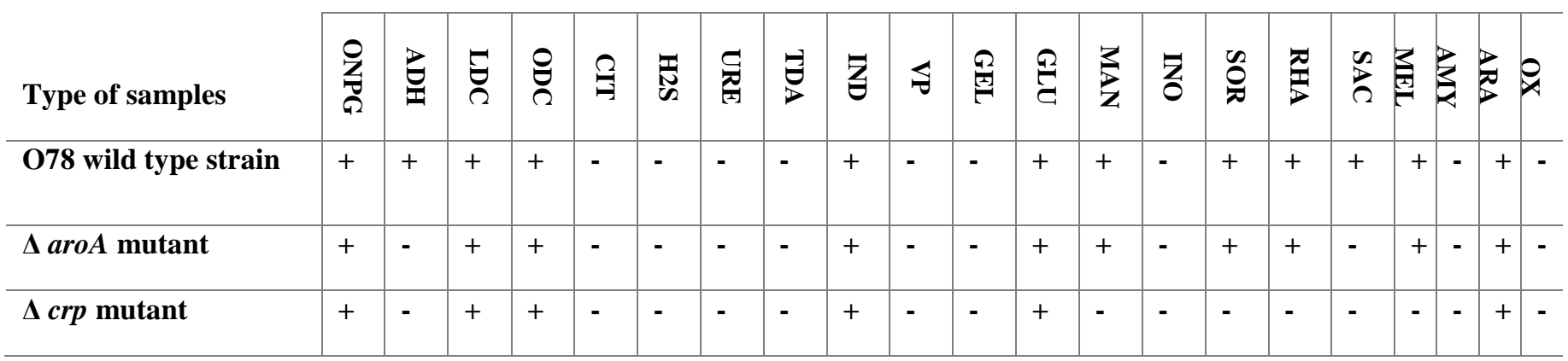

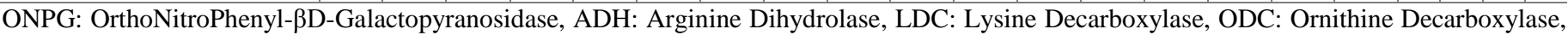
CIT: Citrate utilization, H2S: Hydrogen sulfide, URE: Urease, TDA: Tryptophane Deaminase, IND: Indole, VP: Vages Proskauer, GEL: Gelatin, GLU: Glucose (fermentation/oxidation), MAN: Mannitol (fermentation /oxidation), INO: Inositol (fermentation/oxidation), SOR: Sorbitol (fermentation/oxidation), RHA: Rhamnose (fermentation/oxidation), SAC: Saccharose (fermentation/oxidation), MEL: Melibiose (fermentation/oxidation), AMY: Amygdalin (fermentation/oxidation), ARA: Arabinose (fermentation/oxidation), OX: Oxidase.

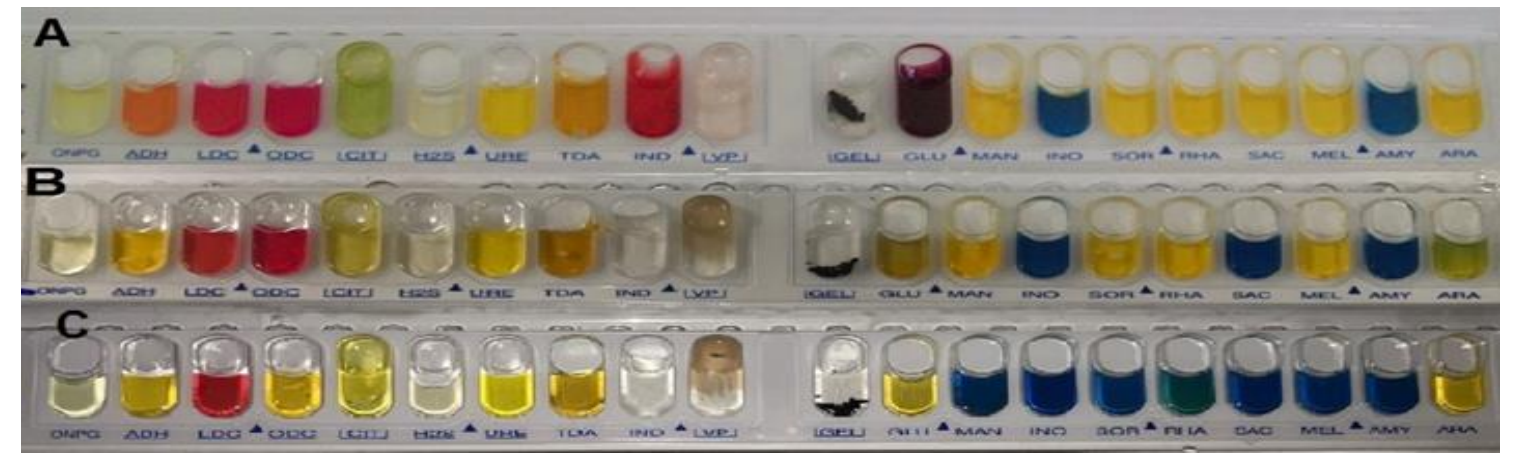

Figure 1. API20E identification system reactions. (A) The wild O78 give positive reaction with ONPG, ADH, LDC, ODC, IND, GLU, MAN, SOR, RHA, SAC, MEL and ARA tests and negative reaction with CIT, H2S, URE, TDA, VP, GEL, INO, AMY and OX tests. (B) aroA deleted vaccinal strain give positive reaction with ONPG, LDC, ODC, IND,GLU, MAN,SOR, RHA, MEL and ARA tests and negative reaction with ADH, CIT, H2S, URE, TDA, VP, GEL, INO, SAC and AMY tests. (C) crp deleted vaccinal strain give positive results with ONPG, LDC, ODC, IND, GLU and ARA tests and negative results with ADH, CIT, H2S, URE, TDA, VP, GEL, MAN, INO, SOR, RHA, SAC, MEL and AMY tests. 
Serotyping: Positive results were obtained when E. coli polyvalent antisera was used with both wild and mutant $E$. coli strains. In the same concern a positive reaction was obtained when monovalent $\mathrm{O} 78$ antisera was used confirming the results of biochemical identification.

Genotypic characterization: The genomic DNAs of the wild type and vaccinal E.coli strains were extracted, electrophoresed on $0.7 \%$ agarose gel and the estimated size of the genomic DNA which was more than $23 \mathrm{kbp}$.

A successful amplification of the 16S rRNA gene were occurred giving rise to a PCR product of $585 \mathrm{bp}$ with the all tested strains as shown in Figure (2) and Table (4) and this confirm that all of the used strains as E.coli.

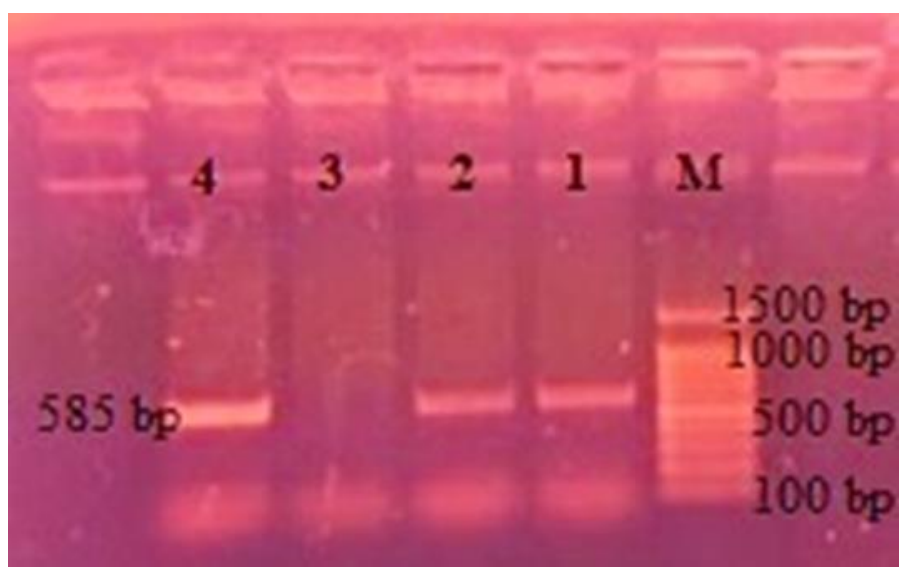

Figure 2. Result of PCR using specific primers of 16s rRNA gene of E. coli. M: marker, Lane 1: $\triangle$ aroA mutant, Lane 2: $\Delta$ crp mutant, Lane 3: Negative control and Lane 4: Wild O78 strain.

As regards to the specific aroA gene primers, it is successfully amplified giving rise aspecific PCR product of $1206 \mathrm{bp}$ with the DNA of wild type and $\Delta$ crp mutant vaccinal strain but not amplified with the DNA of $\triangle \operatorname{aroA}$ mutant as shown in Figure (3) and Table (4).

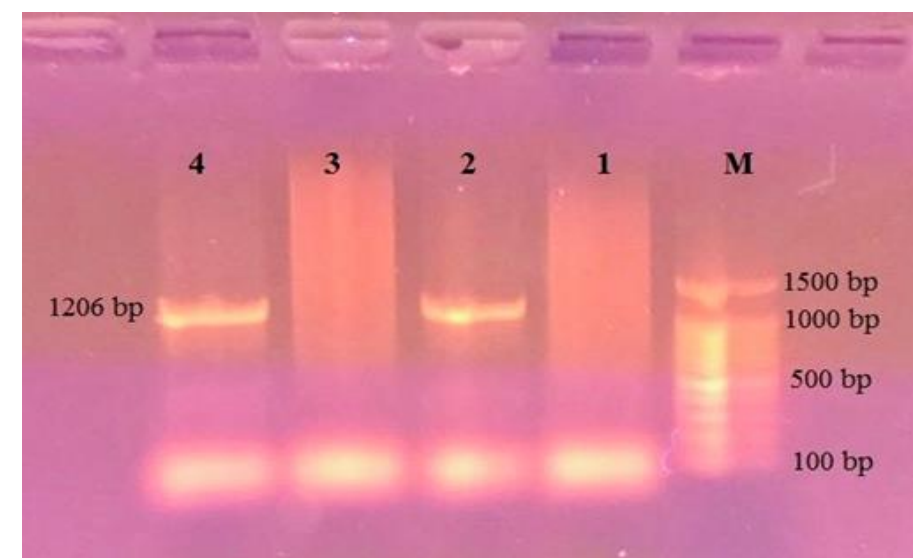

Figure 3. The result of PCR product of aroA gene from whole genomic DNA of E. coli strains. M, marker; Lane 1, $\triangle$ aroA mutant; Lane 2, $\Delta$ crp mutant; Lane 3, -ve control; Lane 4, wild O78 strain.
Regarding crp gene of the examined strains, the specific primer pair was successfully amplified and the PCR product of the amplified products were appeared under the UV transluminator at $1029 \mathrm{bps}$ with only DNA of the wild and $\Delta$ aroA mutant but not with $\Delta$ crp mutant strains as shown in Figure (4) and Table (4).

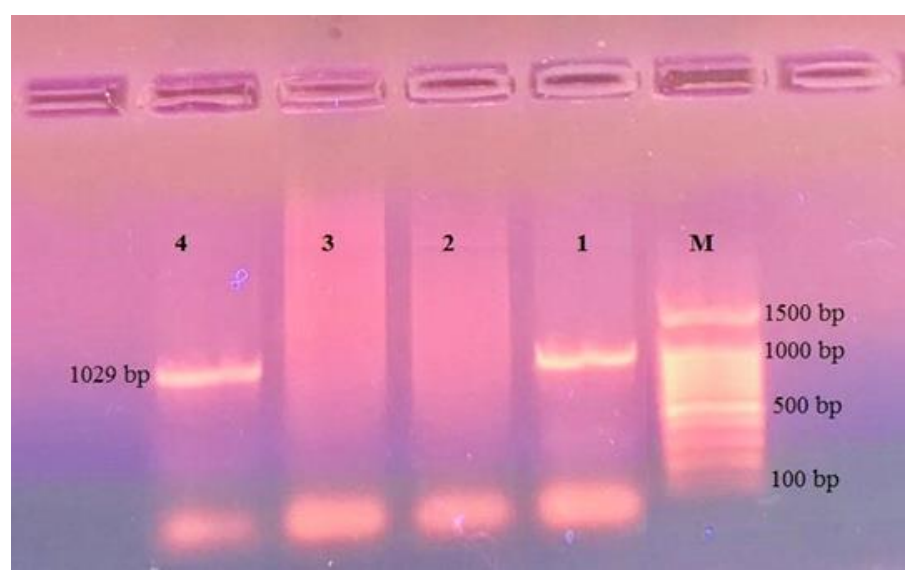

Figure 4. The result of PCR product of crp gene from whole genomic DNA of E. coli strains. M, marker; Lane 1, $\Delta$ aroA mutant; Lane 2, $\Delta$ crp mutant; Lane 3, -ve control; Lane 4, wild O78 strain.

Table 4. PCR amplification of wild and vaccinal E. coli strains.

\begin{tabular}{ccccc}
\hline Samples & No. of & \multicolumn{3}{c}{ Result of PCR } \\
\cline { 3 - 5 } & sample & $\begin{array}{c}\text { 16S } \\
\text { rRNA }\end{array}$ & aroA & crp \\
\hline O78 & 1 & + & + & + \\
\hline$\Delta$ aroA & 2 & + & - & + \\
\hline$\Delta$ crp & 2 & + & + & - \\
\hline Total & 5 & 3 & 2 & 2 \\
\hline
\end{tabular}

\section{Discussion}

In birds $E$. coli infections cause many clinical manifestations with the most important are being airsaculitis, pericarditis, septicemia and may deaths (11). Colibacillosis due to virulent $E$. coli in chickens is characterized by a respiratory manifestation which is frequently followed by a generalized infection (12) resulting in significant economic losses through mortality, morbidity, cost of treatment and carcasses condemnation at processing plant. Live vaccine based on defined mutations that impair virulence is considered one of the most important methods to control the disease. Therefore, proper hygienic measures, accurate vaccination, good surveillance programs and most importantly, reliable detection method to differentiate the wild-type and vaccinal strains of $E$. coli are needed to control this disease (13). In the present study, the phenotypic and genotypic characterizations were used to differentiate between the 
wild-type 078 strain, $\Delta$ aroA and $\Delta$ crp mutant vaccinal strains.

The pattern of growth on different media incubated at $37 \mathrm{C}^{\circ}$ revealed that, the wild type and $\Delta$ aroA mutant demonstrated a large sized rounded, non-pigmented colonies on nutrient agar medium and large sized fermenting rounded, non-mucoid colonies on MacConkey and S.S media as shown in Table (2). These results were confirmed by (14) who stated that aroA deleted bacterial strains such as E. coli and Salmonella are unable to selfproduce aromatic amino acids and p-aminobenzoate that are necessary for their growth and they cannot grow unless such nutrients are supplied from the outside so the aroA gene deleted E. coli strain formulates colonies after $24 \mathrm{hrs}$ of culturing at $37 \mathrm{C}^{\circ}$ on MacConkey and trypticase soya agar media but not on the minimum agar media. On the other hand, the $\Delta \mathrm{crp}$ mutant strain showed small sized rounded, non-pigmented colonies on Nutrient agar medium and small sized non-fermenting rounded, nonmucoid phenotype on MacConkey and S.S media. Also (7) constructed and characterized the avian E. coli $\Delta$ cya crp mutants and confirmed the same difference of colonial size and fermentation characters on MacConkey agar between the wild and mutant strains. Both wild and two mutant strains were Gram negative, motile, non-sporulated, medium sized bacilli as illustrated in Table (2).

As regards to the biochemical activity of the used strains, the API 20E system was used because of the availability of large number of tests which was beneficial when comparing between the wild-type and the two type's mutant strains, in addition to its proven accuracy (15). Depending on the results illustrated in Table (3) and Figure (1), it was clear that the difference between the wild-type and $\triangle$ aroA mutant was inability of the mutant strain to produce ADH (argenine dihydrase) and fermentation of saccharose. On the other hand the $\Delta$ crp mutant failed to produce $\mathrm{ADH}$ and to ferment any of the carbohydrates (MAN, INO, SOR, RHA, SAC and MEL) except glucose (GLU). The same finding obtained by (7). Positive results were obtained when $E$. coli polyvalent antisera was used with both wild and mutant E. coli strains. In the same concern a positive reaction was obtained when monovalent $\mathrm{O} 78$ antisera was used confirming the results of biochemical identification.

The wild $E$. coli strains are usually identified by detection of a specific virulence factor (16) such as aroA that codes 5-enolpyruvylshikimate 3-phosphate synthase, one of enzymes that govern the shikimate pathway for synthesizing aromatic amino acids involved with the growth and metabolism of bacteria and crp gene (gene encode for cAMP receptor protein) which is a regulatory molecule that are required for satisfactory operation of many genes involved in transport and breakdown of nutrients in bacteria. Deletion of such genes impairs the growth and metabolism of bacteria so the live vaccines based on defined mutations of these genes have been shown to reduce the virulence of $E$. coli strains. In the present study these genes were amplified to differentiate between the wild and vaccinal strains.

Firstly the genomic DNAs of the wild type and vaccinal $E$. coli strains were extracted, and its estimated size was more than $23 \mathrm{kbp}$. The used strains were confirmed as E. coli by successful amplification of the $16 \mathrm{~S}$ rRNA gene giving rise to a PCR product of $585 \mathrm{bp}$ with the all tested strains as shown in Figure (2) and Table (4). The same product obtain by (17) who identified E. coli isolated from naturally healthy broiler chickens in Bangladesh by PCR using the same primer and (10) who used PCR to detect the pathogenic E. coli through pathological study of the colibacillosis affected birds.

Regarding the amplification using specific aroA gene primers, it is successfully amplified giving rise aspecific PCR product of $1206 \mathrm{bp}$ with the wild type and $\Delta$ crp mutant vaccinal strain DNAs but not amplified with $\Delta$ aroA mutant DNA as shown in Figure (3) and Table (4). These results has been found by (6) who constructed a genetically defined aroA mutant of a native $E$. coli O78:K80 isolated from avian colibacillosis in Iran. On the same concern, crp genes of the examined strains were tested and successfully amplified using its specific primers and the PCR amplicon was 1029 bps with the DNAs of wild and $\triangle$ aroA mutant strains but not with $\Delta$ crp mutant strain as shown in Figure (3) and Table (4). (7) obtain the same product when constructed and characterized avian E. coli cya crp mutants.

Multiplex PCR using the different three primers sets can be optimized and this may support results obtained in this work as the analyst can achieve his request in only one step and this will save either more time or effort to detect the presence or absence of the aroA, crp or $16 S$ rRNA genes.

\section{Conclusion}

From the obtained findings in this study, the use of methods based on molecular biological techniques such as PCR provides accurate, specific and sensitive discrimination of wild type from vaccinal mutant strains (13). Also, this study can help to differentiate between different types of $E$. coli strains either wild or vaccinal mutant type strains. In addition to, this study may help in exclusion or proving the return back to virulence of the mutant vaccinal strain of $E$. coli through following epidemiologically these scheme or plan of work.

Ethics Committee Approval: N.A.

Informed Consent: N.A.

Peer-review: Externally peer-reviewed. 
Conflict of Interest: No conflict of interest was declared by the author.

Financial Disclosure: The author declared that this study has received no financial support.

\section{References}

1. De Silveira WD, Lancellotti M, Ferreira A, Solferini VN, De Castro AFP, et al. Determination of the clonal structure of avian E. coli strains by isoenzyme and ribotyping analysis. J Vet Med. B, Infectious diseases and Veterinary Public Health. 2003; 50: 63-69.

2. Prukner E. Frequency and epidemiological significance of virulent Escherichia coli strains in dead poultry. Vet Archive. 1986; 56: 227-237.

3. Cloud S S, Rosenberger JK, Fries PA, Wilson RA, Odor EM. In-vitro and in-vivo characterization of avian Escherichia coli I: serotypes, metabolic activity and antibiotic sensitivity. Avian Dis. 1985; 29: $1084-1093$.

4. Chart H, Smith HR, La Ragione R M and Woodward M J. An investigation into the pathogenic properties of Escherichia coli strains BLR, BL21， DH5 $\alpha$, and EQ1. J Appl Microbiol. 2000; 89: 1048 - 1058.

5. Formmer AP, Freildlin R, Litner G, Chaffer M and Heller ED. Expermintal vaccination of young chickens with alive nonpathogenic strain of Escherichia coli. Avian Path. 1994; 23: 425433.

6. Fasaei BN, Salehi TZ, Tadjbakhsh H, Firuzi R, Casadesus J. Construction of genetically defined aro A mutant of a native $\mathrm{E}$. coli O78:K80 isolated from avian colibacillosis, in Iran. Comp Clin Pathol. 2009; 18: 69-75.

7. Peighambari SM, Gyles CL. Construction and characterization of avian E. coli cya crp mutants. Avian Dis. 1998; 42: 698-710.

8. Ghanbarpour R, Salehi M, Oswald E. Virulence genotyping of $\mathrm{E}$. coli isolates from avian cellulites in relation to phylogeny. Comp Clin Pathol. 2010; 19: 147-153.

9. Sojka WJ. In "Escherichia coli in domestic animals and poultry" 1 st edd. Commonwealth Agriculture. Bureau, Farnham, Royal Buck, England. 1965; pp. 104-156.

10. Tonu NS, Sufian MA, Sarker S, Kamal MM, Rahman MH, and Hossain MM. Pathological study on colibacillosis in chickens and detection of E. coli by PCR. Bangl J Vet Med. 2011; 9: 17-25.

11. Vidotto M C, Muller E E, De Freitas J C, Alfieri A A, Guimaraes I G, and Santos D S. Virulence factors of avian E. coli. Avian Diseases. 1990; 34: 531-538.

12. Gross R J. Acute enteritis P.458-476. In Topley and Wilson's Principles of Bacteriology, Virology and Immunity. 1984; 7th Ed. Vol.3. Bacterial Diseases Butley, Tanner Ltd. Forme.

13. Dong XY, Li WH, Zhu JL, Liu WJ, Zhao MQ, Luo YW, et al. Detection and differentiation of wild-type and vaccine strains of canine distemper virus by a duplex reverse transcription. PCR. IJVR. 2014; 16: 172-175.

14. Kariyawasam S. Construction, characterization and evaluation of the vaccine potential of three genetically defined mutants of avian pathogenic E. coli. Avian Dis. 2004; 48: 287299.

15. Willis G and Cook WY. A comparative study of API, Encise and conventional methods. Med Technologist. 1975; ed. 5:4. 16. Hasina B. Enteropathogenic characterization of E. coli isolated from diarrhoeic calves and their antibiogram study. M.S. thesis, Department of Microbiology and Hygiene, BAU, Mymensingh, 2006; p. 68.

17. Khatun MN, Mahbub ATM, Ahmed S, Parvej MS, Akhter $\mathrm{S}$, Ansari WK, et al. Frequency of drug resistant E. coli isolated from commercial broiler chicken in Bangladesh. Int J Nat Soc Sci. 2015; 2: 1-5.

Submit your next manuscript to the JICM and take full advantage of:

- Convenient online submission,

- Thorough peer review, Fast Response,

- No charges,

- Immediate publication on acceptance,

- Inclusion in Scopemed and High quality indexes,

- Research which is freely available for redistribution of the worldwide literature

To submit your manuscript, click on http://www.jiacm.com

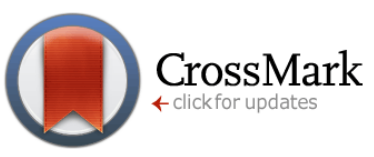

Published by The QMEL.org International Medical Education Library

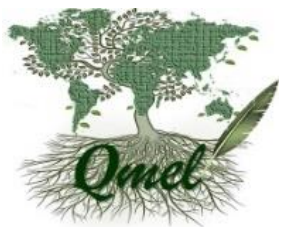

